\title{
MESH ANOPLASTY- AN UNIQUE APPROACH TO RECTAL PROLAPSE
}

\author{
D. N. Renganathan', R. Jayakumar², V. S. Venkadesan 3 , P. Viggnesh', D. J. Balaji ${ }^{5}$ \\ 1 Professor, Department of General Surgery, Coimbatore Medical College Hospital, Coimbatore. \\ ${ }^{2}$ Assistant Professor, Department of General Surgery, Coimbatore Medical College Hospital, Coimbatore. \\ ${ }^{3}$ Assistant Professor, Department of General Surgery, Coimbatore Medical College Hospital, Coimbatore. \\ ${ }^{4}$ Postgraduate Student, Department of General Surgery, Coimbatore Medical College Hospital, Coimbatore. \\ 5 Postgraduate Student, Department of General Surgery, Coimbatore Medical College Hospital, Coimbatore.
}

\begin{abstract}
\section{BACKGROUND}

Rectal prolapses are not life-threatening; however, the bleeding and faecal incontinence associated with them significantly erode quality of life and can cause concern among patients, caregivers in nursing homes. Many procedures have been reported that repair of rectal prolapses and the procedure used depends on the severity of the prolapsed[1]; however, the treatments are yet to be established. Here, we report a simple and safe procedure to repair rectal prolapse perineally using non-absorbable polypropylene mesh for anoplasty. We performed this procedure on 10 patients. All patients were followed up for over 3 years and none had any recurrences of their rectal prolapses. No complications occurred during the operations and postoperative periods. Most patients who have prolapses are elderly and fragile, so the treatment must be easy, safe and rapid. While rectal prolapse is not life-threatening, the goal of treatment is to alleviate its symptoms. The procedure we describe is consistent with this concept. We suggest that this procedure, which uses non-absorbable polypropylene mesh, might be a better option for the treatment of complete rectal prolapse. We will continue to surgically correct complete rectal prolapses and investigate the long-term outcomes of the procedure.
\end{abstract}

\section{KEYWORDS}

Rectal Prolapse, Non-absorbable Polypropylene Mesh, Anoplasty.

HOW TO CITE THIS ARTICLE: Renganathan DN, Jayakumar R, Venkadesan VS, et al. Mesh anoplasty - an unique approach to rectal prolapse. J. Evolution Med. Dent. Sci. 2017;6(16):1303-1304, DOI: 10.14260/Jemds/2017/282

\section{BACKGROUND}

Rectal prolapse usually occurs in older patients, particularly females. Although not life-threatening, rectal prolapses can significantly erode quality of life and can cause concern among patients' caregivers. Many procedures are reported to repair rectal prolapse and the procedure used depends on the severity of the prolapse and the status of the patient. $[2,3,4,5,6]$ However, surgical intervention is the mainstream treatment. In elderly and fragile patients, perineal approaches are preferred; for example, Delorme's procedure with or without the Thiersch procedure and the Gant-Miwa procedure are options for mild rectal prolapse, whereas Altemeier's procedure is the treatment of choice for severe rectal prolapse. Abdominal approaches such as rectopexy, resection and fixation and recently laparoscopic approaches are popular and are generally applied in younger patients. However, these procedures are time-consuming. They demand advanced surgical techniques and the recurrence rate is not low.[7] Here, we report a simple procedure that repairs rectal prolapse perineally by using non-absorbable mesh for anoplasty.

\section{MATERIALS AND METHODS}

Study Area

Coimbatore Medical College Hospital [CMCH], Coimbatore.

Financial or Other, Competing Interest: None.

Submission 18-01-2017, Peer Review 12-02-2017,

Acceptance 17-02-2017, Published 23-02-2017.

Corresponding Author:

Dr. D. N. Renganathan,

Professor,

Department of General Surgery,

Coimbatore Medical College Hospital, Coimbatore.

E-mail:dnrengs@gmail.com

DOI: $10.14260 /$ jemds $/ 2017 / 282$

\section{(c) (i) $\odot$}

\section{Study Population}

Patients admitted in $\mathrm{CMCH}$ with complete rectal prolapse.

\section{Study Period}

3 years from January 2014 - December 2016

\section{Sample Size}

10 patients with rectal prolapse.

Preoperative evaluation of the patients was done for the surgical procedure under spinal anaesthesia.

\section{Surgical Procedure \\ Mesh Anoplasty}

The patient is placed in a lithotomy position under spinal anaesthesia, parts painted and draped. The rectal prolapse was reduced completely. A small vertical incision of $0.5 \mathrm{~cm}$ made at 12 'o clock and 6'o clock position of anal opening. Subcutaneous tunneling done in between the incisions around the anus without disturbing the anal sphincter muscles. The mesh is folded along its length and sutured with prolene to create a bilayered mesh. The bilayered mesh is introduced in the subcutaneous tunnel created all around the anus. Anal canal size is planned and the mesh approximated accordingly and removed, excess mess cut. Incision site is sutured and sterile dressing is applied.

\section{RESULTS}

Since 2014, we have performed this procedure in 10 patients. Out of them, there were 6 females and 4 males. None of the patients had recurrence or mesh rejection/infection. Only one patient, a known cardiac patient (CAD) developed difficulty in defecation leading to respiratory distress. So, mesh removal was done to increase the anal patency for easy defecation. Mean age of the patient is 68 years. The maximum duration of surgery was 24 minutes and minimum duration was 14 
minutes. Mean duration of surgery is 19.2 minutes. Postoperatively, no severe complications such as bleeding abscesses occurred. All patients were followed up for over 3 years and none had any recurrences of their rectal prolapses.

\begin{tabular}{|c|c|c|c|c|c|c|c|c|}
\hline 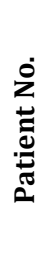 & 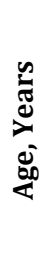 & $\stackrel{\star 凶}{凶}$ & 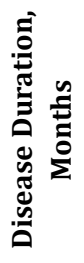 & 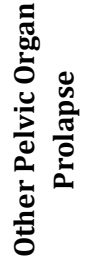 & 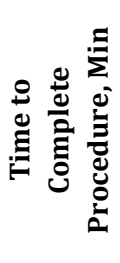 & 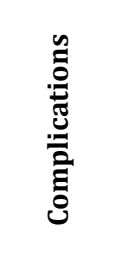 & 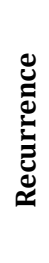 & 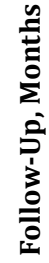 \\
\hline 1 & 70 & Female & 1 & - & 20 & - & - & 33 \\
\hline 2 & 56 & Male & 2 & - & 24 & - & - & 30 \\
\hline 3 & 86 & Female & 2 & - & 22 & - & - & 28 \\
\hline 4 & 72 & Female & 6 & - & 22 & - & - & 25 \\
\hline 5 & 80 & Female & 2 & - & 18 & $\begin{array}{c}\text { Anal } \\
\text { Stenosis }\end{array}$ & - & 22 \\
\hline 6 & 66 & Male & 4 & - & 20 & - & - & 19 \\
\hline 7 & 59 & Male & 2 & - & 15 & - & - & 17 \\
\hline 8 & 61 & Female & 1 & - & 17 & - & - & 14 \\
\hline 9 & 54 & Male & 2 & - & 18 & - & - & 10 \\
\hline 10 & 76 & Female & 1 & - & 16 & - & - & 8 \\
\hline \multicolumn{9}{|c|}{$\begin{array}{c}\text { Table 1. Patient Demographics and Outcomes of the } \\
\text { Procedure to Repair Rectal Prolapses }\end{array}$} \\
\hline
\end{tabular}

\section{DISCUSSION}

Rectal prolapse usually occurs in older patients, particularly females. Although, rectal prolapses are not life-threatening, the bleeding and fecal incontinence associated with them significantly erode quality of life and can cause concern among patients' caregivers in nursing homes. Given that rectal prolapse is associated with aging and its prevalence has risen recently, it appears that rectal prolapse will become a serious problem with aging population.

The following two types of rectal prolapse can occur: complete prolapse and incomplete prolapse.[2] A complete prolapse is defined as a protrusion of the full-thickness colon/rectal wall, whereas an incomplete prolapse is defined as a protrusion of the rectal wall within the anal canal. The treatment options differ for each condition and here we describe surgical treatment for the complete rectal prolapse. The various anatomical and physiological abnormalities causing rectal prolapse.

\section{Rectal Prolapse Anatomic Abnormalities}

- Deep cul-de-sac.

- Redundant sigmoid colon.

- Poor sacral fixation.

- Lax in the lateral ligaments.

\section{Rectal Prolapse Physiologic Abnormalities}

- Atonic levator ani muscles.

- External anal sphincter weakness.

- Non-relaxing puborectalis.

- Pudendal nerve injury.
Many procedures have been reported on repair of rectal prolapses and the procedure used depends on the severity of the prolapsed[1]; however, the treatments are yet to be established. In terms of perineal approaches, Delorme's procedure and the Gant-Miwa procedure might be feasible for mild prolapses in the elderly, whereas Altemeier's procedure is the surgical option of choice for severe rectal prolapses. Abdominal approaches such as rectopexy, resection and fixation, and recently laparoscopic approaches are also widely performed in younger patients. However, these procedures tend to be time-consuming, they demand advanced surgical techniques and the recurrence rate is not low. $[3,4,5,6,7]$

Here, we report a simple procedure that repairs rectal prolapse perineally by using non-absorbable mesh for anoplasty. The indications for this procedure is complete rectal prolapse, old age and associated with other comorbidities. We have performed this procedure in 10 patients and got an excellent outcome. Most patients who have prolapses are elderly and fragile, so the treatment must be easy, safe and rapid. While rectal prolapse is not lifethreatening, the goal of treatment is to alleviate its symptoms.

\section{CONCLUSION}

This procedure (MESH ANOPLASTY) is found very good and effective in adults, cheap and simple, and if there are any complications removal of mesh is also a very easy procedure. Hence, we suggest that this procedure which uses nonabsorbable mesh might be a better option for the treatment of complete rectal prolapse.

We will continue to surgically correct complete rectal prolapses and investigate the long-term outcomes of the procedure.

\section{REFERENCES}

[1] Shin EJ. Surgical treatment of rectal prolapse. J Korean Soc Coloproctol 2011;27(1):5-12.

[2] Hata F, Kitagawa S, Nishimori H, et al. A novel, easy, and safe technique to repair a stoma prolapse using a surgical stapling device. Dig Surg 2005;22(5):306-9.

[3] Bachoo P, Brazzelli M, Grant A. Surgery for complete rectal prolapse in adults. Cochrane Database Syst Rev 2000;(2):CD001758.

[4] Eu KW, Seow-Choen F. Functional problems in adult rectal prolapse and controversies in surgical treatment. Br J Surg 1997;84(7):904-11.

[5] Ris F, Colin JF, Chilcott M, et al. Altemeier's procedure for rectal prolapse: analysis of long-term outcome in 60 patients. Colorectal Dis 2012;14(9):1106-11.

[6] Fleming FJ, Kim MJ, Gunzler D, et al. It's the procedure not the patient: the operative approach is independently associated with an increased risk of complications after rectal prolapse repair. Colorectal Dis 2012;14(3):362-8.

[7] Sajid MS, Siddiqui MR, Baig MK. Open vs laparoscopic repair of full-thickness rectal prolapse: a re-metaanalysis. Colorectal Dis 2010;12(6):515-25. 